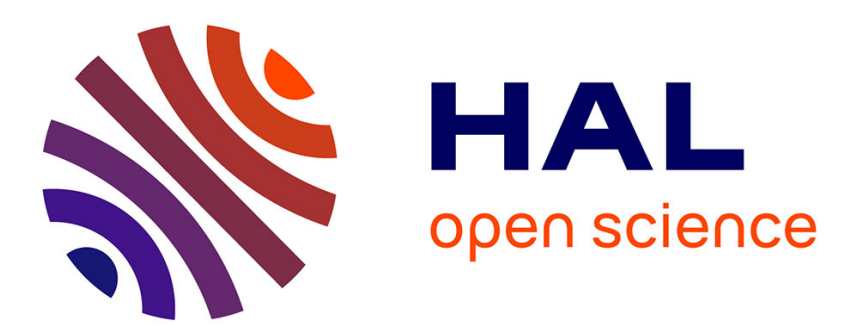

\title{
Thermally stimulated currents in undoped and doped zinc phthalocyanine films
}

B. Boudjema, N. El-Khatib, M. Gamoudi, G. Guillaud, M. Maitrot

\section{To cite this version:}

B. Boudjema, N. El-Khatib, M. Gamoudi, G. Guillaud, M. Maitrot. Thermally stimulated currents in undoped and doped zinc phthalocyanine films. Revue de Physique Appliquée, 1988, 23 (6), pp.11271134. 10.1051/rphysap:019880023060112700 . jpa-00245915

\section{HAL Id: jpa-00245915 https://hal.science/jpa-00245915}

Submitted on 1 Jan 1988

HAL is a multi-disciplinary open access archive for the deposit and dissemination of scientific research documents, whether they are published or not. The documents may come from teaching and research institutions in France or abroad, or from public or private research centers.
L'archive ouverte pluridisciplinaire HAL, est destinée au dépôt et à la diffusion de documents scientifiques de niveau recherche, publiés ou non, émanant des établissements d'enseignement et de recherche français ou étrangers, des laboratoires publics ou privés. 


\title{
Thermally stimulated currents in undoped and doped zinc phthalocyanine films
}

\author{
B. Boudjema, N. El-Khatib, M. Gamoudi, G. Guillaud and M. Maitrot \\ Laboratoire d'Electronique des Solides, Université Claude Bernard, Lyon I, \\ 43 Boulevard du 11 Novembre 1918, 69622 Villeurbanne Cedex, France
}

(Reçu le 28 septembre 1987, révisé le 19 janvier 1988, accepté le 22 février 1988)

\begin{abstract}
Résumé. - La méthode des courants thermostimulés est utilisée pour étudier le transport contrôlé par le piégeage dans les films de Phtalocyanine de Zinc non dopés et dopés. Un mécanisme de Poole Frenkel est mis en évidence dans un intervalle de tensions appliquées comprises entre 0,5 et $2 \mathrm{~V}$. On a simultanément étudié la réponse diélectrique de ces échantillons dans un intervalle étendu de fréquences. Une discussion des résultats expérimentaux est donnée.
\end{abstract}

\begin{abstract}
The thermally stimulated current method is used to study the trap controlled carrier transport in Zinc Phthalocyanine films $(1.2 \mu$ thick) undoped and $n$ and $p$ doped. A Poole Frenkel mechanism is pointed out in a given range $(0.5,2 \mathrm{~V})$ of applied voltage. Some $\mathrm{AC}$ curves in a large frequency and temperature ranges were also recorded. A discussion of the experimental data is given.
\end{abstract}

\section{Introduction.}

Trap levels, capture cross sections and conduction mechanisms can be evaluated in insulating or semiconducting materials from thermally stimulated currents (TSC). This method was used in numerous inorganic or organic semiconductors [1-6]. However the interpretation of experimental measurements often requires the knowledge of recombination kinetics and of the distribution of the distribution of trap depths.

Likewise, only one trap level is considered in many cases. This symplifying hypothesis is more justified and even very likely in doped materials where one kind of defects prevails. Indeed, the depth of the most part of the traps is then characteristic of the doping agent and, to a first approximation, can be evaluated in two complementary ways.

a) Some theoretical evaluations of the ability of doping have been made by a first way related to the electrochemical model of Lyons [7]. Lyons pointed out a very general method of gap evaluation in organic materials, and this method can be used as a test of doping availability in these materials.

The gap of a molecular material is given by :

$E_{\mathrm{g}}=\left[e E^{\mathrm{ox}}-e E^{\mathrm{red}}\right]+\left(S^{-}+S^{+}\right)_{\text {liq }}\left(1-P_{\mathrm{s}} / P_{\text {liq }}\right)$ where $e$ is the electronic charge, $E^{\mathrm{ox}}$ and $E^{\mathrm{red}}$ are the redox potentials and $S^{-}$and $S^{+}$the solvatation energies of the negative and positive ions in solution, $P_{\mathrm{s}}$ and $P_{\text {liq }}$ the polarization energies in the solid and in the solution.

In the case of Phthalocyanines, $P_{\mathrm{s}} / P_{\text {liq }} \approx 0.75$, and on the whole, the second term of (1) is far lesser than the first one.

Then using the redox potentials, the band gap of each material can be determined. A $p$ doping effect can be predicted if $E_{\text {ox }}$ of the dopant is larger than $E_{\text {ox }}$ of the doped material and then the charge transfer is total [8]. On the other hand if $E^{\text {red }}$ (Host $)<E^{\text {ox }}$ (Dopant $)<E^{\text {ox }}$ (Host $)$, the transfer is only partial and characteristic charge transfer states are created in the gap of the host.

Similarly a $n$ doping effect with a total transfer occurs when $E^{\text {red }}$ (dopant) is larger than $E^{\text {red }}$ (host) and characteristic charge transfer states can be created in the gap of the doped material when :

$E^{\text {ox }}($ Host $)<E^{\text {red }}($ dopant $)<E^{\text {red }}($ Host $)$.

(Fig. 1b.1)

b) An other method can also be applied: the determination by theoretical calculations of HOMO and LUMO levels of host and dopant $[8,9]$. The respective positions of these levels can predict the ability of a doping effect (Fig. 1b.2). 


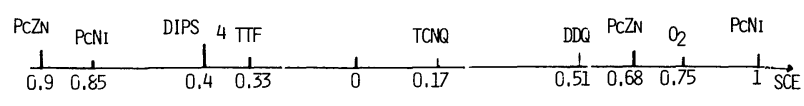

a)

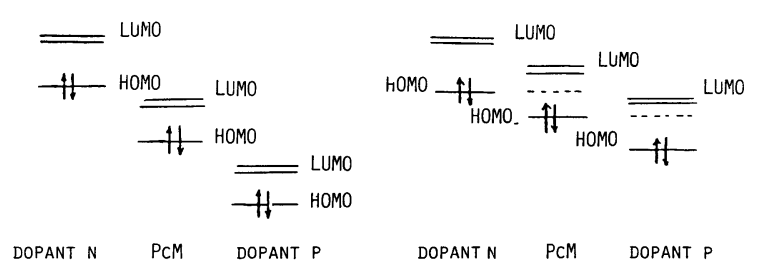

b)

Fig. 1. - a) Redox potentiels, b) HOMO and LUMO levels of ZnPc, TCNQ and DIPS $\phi_{4}$.

On the other hand in undoped material some levels were found: Oxygen levels (Oxygen cannot be thoroughly removed from the sample) or other chemical or structural defects. The thermocurrent results are always more readily analysable with doped samples and so the doped samples will be first studied.

We used two dopants :

- Tetracyanoquinodimethane (TCNQ, $p$ dopant) dopant).

Therefore, the aim of our work is chiefly experimental but the good agreement between the data and the theoretical trap levels due to the dopant will also be investigated.

\section{Experimental.}

2.1 Materials. - The Zinc Phthalocyanine $(\mathrm{ZnPc})$ was purified by successive sublimations and supplied by J. J. André (Institut C. Sadron, Strasbourg) and DIPS $\phi_{4}$ was synthetized by H. Strezlecka (ESPCI, Paris) - TCNQ was commercially available.

2.2 Films Elaboration. - The sandwich geometry was used. A gold electrode was first evaporated on to a microscope glass plate carefully cleaned.

Then the cosublimation method [10] was used for doped samples (Fig. 2b). Two small ovens with a very precise temperature stabilization, are monitored to control simultaneously and automatically the evaporation rates. The proportion of dopant was constant through the sample bulk (it can be varied from a $1 / 1$ to $2 / 100$ in mass, with a good stability during the whole evaporation time).

In TSC experiments we used three kinds of samples : undoped samples, TCNQ doped samples (20\% in moles) and DIPS $\phi_{4}$ (10\% in moles) doped samples.

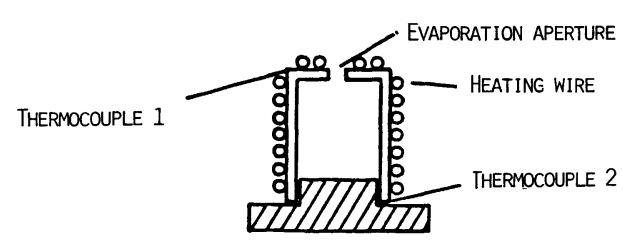

Fig. 2.1.

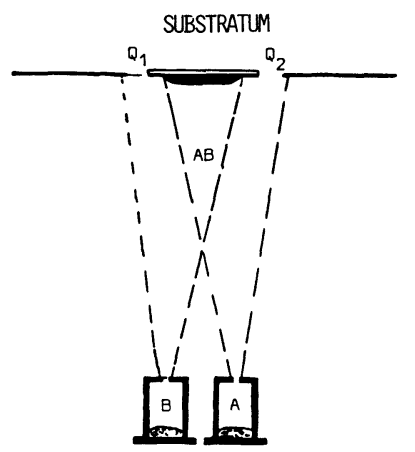

a)

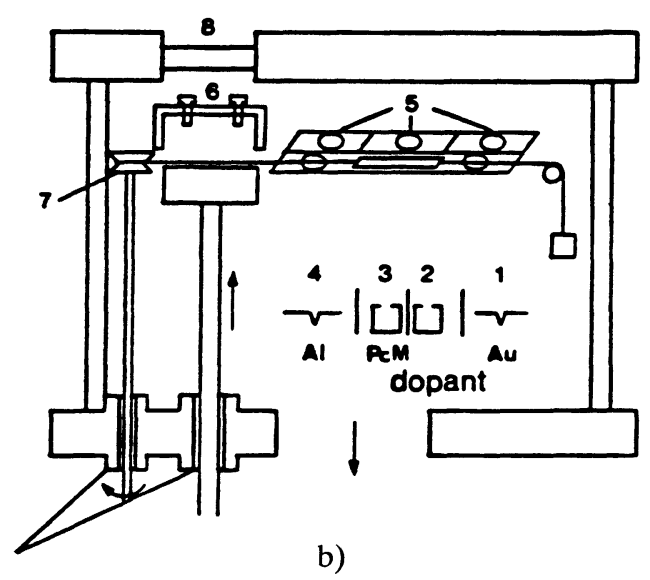

Fig. 2.2.

Fig. 2. - Coevaporation apparatus.

A gold counter electrode is finally evaporated. The cell thicknesses are about $1.2 \mu$.

2.3 TSC EXPERIMENTS. - The samples are first polarized at the room temperature with a low voltage $(0$ to $5 \mathrm{~V}$, doped samples -0 to $20 \mathrm{~V}$, undoped samples). Then the temperature is lowered to the liquid Nitrogen temperature with the polarizing voltage applied. Afterwards the sample is short circuited during about $20 \mathrm{~s}$ and the temperature is linearly and slowly raised, the thermocurrent being recorded in short circuit [11].

Some experimental results are given (Figs. 3 to 5). With the large DIPS $\phi_{4}$ molecules, the experimental results are very reproducible, but with TCNQ a little part of dopant can be evaporated during each process and the thermocurrent peak can be somewhat lowered after several temperature cycles. 


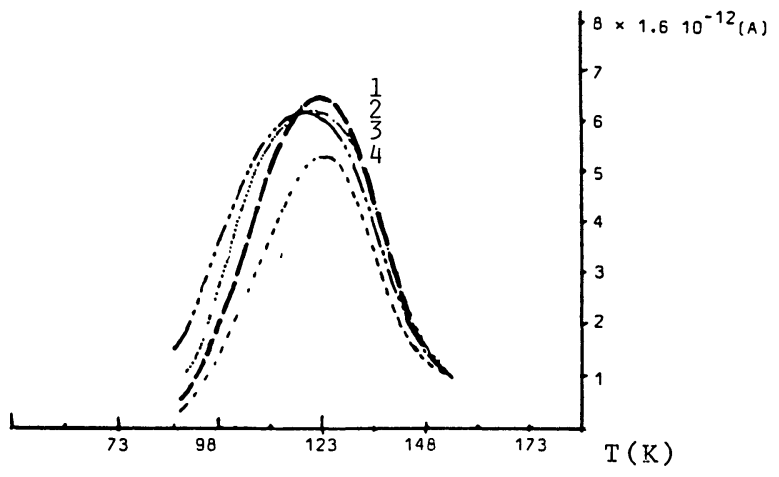

Fig. 3. - TSC with DIPS $\phi_{4}$ doped samples : Au/ZnPc, DIPS $\phi_{4} / \mathrm{Au}$ cell ; 1) $6 \mathrm{~V}$; 2) $4 \mathrm{~V}$; 3) $2 \mathrm{~V}$; 4) $1 \mathrm{~V}$. $\beta=0.066 \mathrm{~K} / \mathrm{s}$.

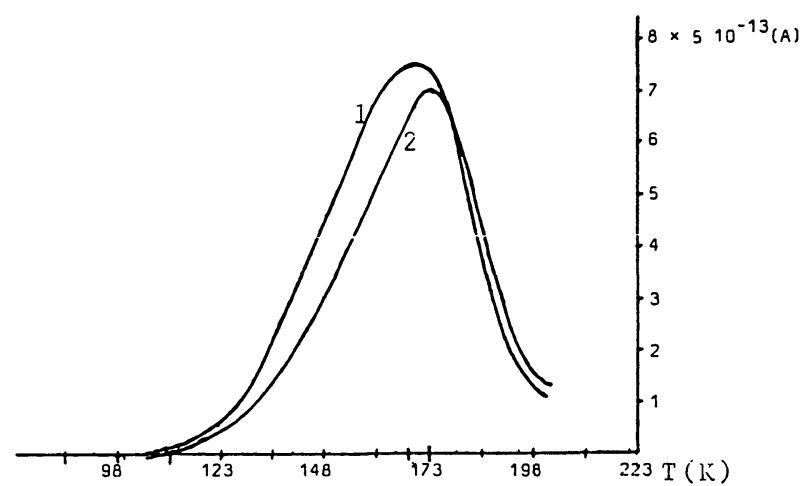

Fig. 4. - TSC with TCNQ doped samples : $\mathrm{Au} / \mathrm{ZnPc}$, $\mathrm{TCNQ} / \mathrm{Au}$ cell ; 1) $1 \mathrm{~V}$; 2) $0.5 \mathrm{~V}$. $\beta=0.066 \mathrm{~K} / \mathrm{s}$.

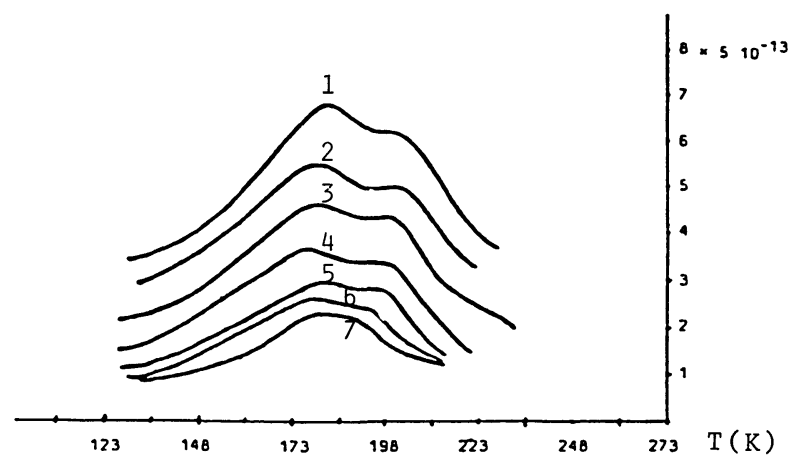

Fig. 5. - TSC with $\mathrm{ZnPc}$ undoped samples : $\mathrm{Au} / \mathrm{ZnPc} / \mathrm{Au}$ cell ; 1) $20 \mathrm{~V}$; 2) $16 \mathrm{~V}$; 3) $12 \mathrm{~V}$; 4) $8 \mathrm{~V}$; 5) $4 \mathrm{~V}$; 6) $2 \mathrm{~V}$; 7) $1 \mathrm{~V}$. $\beta=0.066 \mathrm{~K} / \mathrm{s}$.

However, for different samples, with the same doping ratio, the same time and polarization voltage, relatively large discrepancies on the temperature of the maximum $\left(T=T_{\mathrm{m}}\right)$ are obvious. In table $\mathrm{I}$, these discrepancies can be as high as $15 \mathrm{~K}$, but they are much smaller on a given sample (1-2 K).

This can be related to the sample elaboration. In fact, a low evaporation rate must always be kept to get available PcZn layers : the maximum of this rate is about $20 \AA / \mathrm{s}$. So it is difficult to obtain a low doping ratio, because the doping species must then be evaporated at a very low rate (for instance $2 \AA / s$ ) during all the evaporation time ( $>1$ hour). The value of $T_{\mathrm{m}}$ (TSC temperature maximum) and of the conductivity depends on this ratio in a somewhat complicated way [8] : with the low $(<5 \%)$ doping ratio $\delta$, the conductivity increases with $\delta$ (and $T_{\mathrm{m}}$ decreases), but with higher values of $\delta(>10 \%)$ the conductivity decreases with $\delta$. In spite of this difficulty, the results are really very clear and easier to interpret when the samples are doped : the peaks are well characterized and somewhat enlarged with respect to Debye peaks. Their height is linear with voltage with low polarizing voltages $V<0.5 \mathrm{~V}$. However a saturation appears when $V>0.5 \mathrm{~V}$ and then the maximum of thermocurrent is moved to lower temperatures.
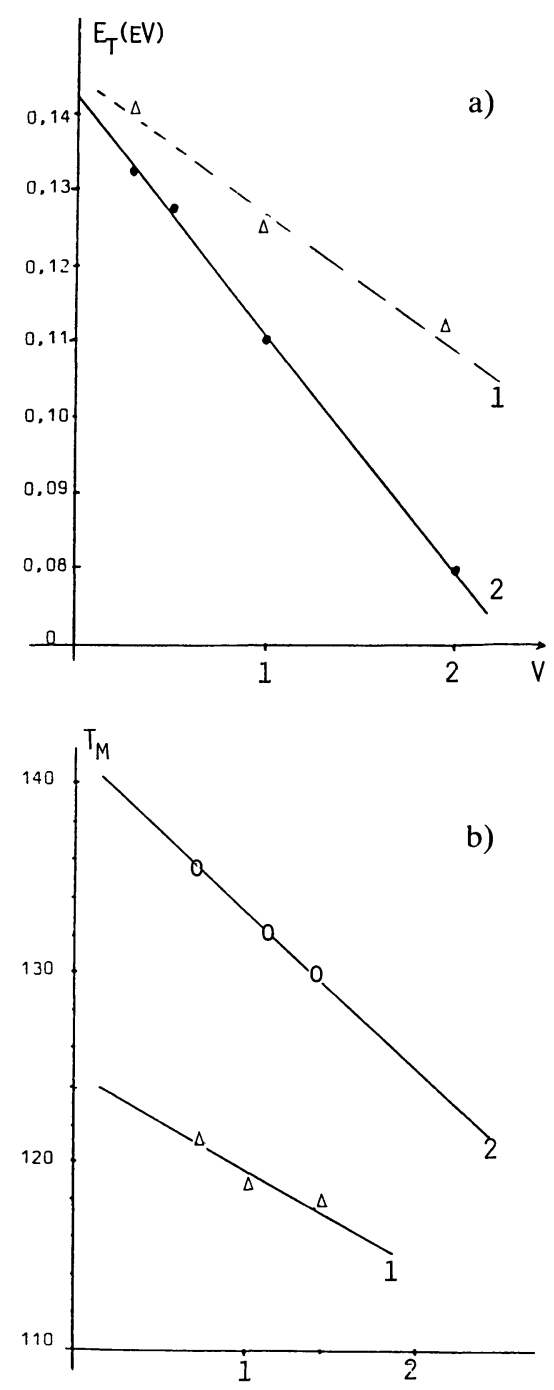

Fig. 6. - a) Trap depth $E_{\mathrm{t}}$ versus polarization voltage ; 1) $\mathrm{Au} / \mathrm{ZnPc}, \mathrm{TCNQ} / \mathrm{Au}$; 2) $\mathrm{Au} / \mathrm{ZnPc}$, DIPS $\phi_{4} / \mathrm{Au}$; b) Temperature of the maximum $T_{\mathrm{m}}$ of the TSC versus ; polarization voltage ; 1) $\mathrm{Au} / \mathrm{ZnPc}, \mathrm{TCNQ} / \mathrm{Au}$; 2) $\mathrm{Au} / \mathrm{ZnPc}$, DIPS $\phi_{4} / \mathrm{Au}$. 
On the other hand, in the undoped case, some discrepancies can be observed between different samples. These discrepancies are likely related to elaboration process (evaporation rate, sublimation temperature, etc...). We obtain a broad maximum, at much higher temperatures. This broad peak (Fig. 5) is also linear with voltage in the low voltages range ; for higher voltages $(0.5<V<2 \mathrm{~V})$, a saturation is seen and for higher voltages the linearity is again obvious. Sometimes two peaks are seen (Fig. 5) corresponding to several kinds of chemical or structural impurities.

2.4 DC MEASUREMENTS. - Electrical $I(V)$ DC curves were also recorded : on figure $7, \log I$ versus $V^{1 / 2}$ curves are given for two samples, the first one for a DIPS $\phi_{4}$ doped sample and the second for an undoped sample. The Poole Frenkel [13-15] effect corresponding to assisted field detrapping is then obvious between $0.5 \mathrm{~V}$ and $2 \mathrm{~V}$ in the two samples.
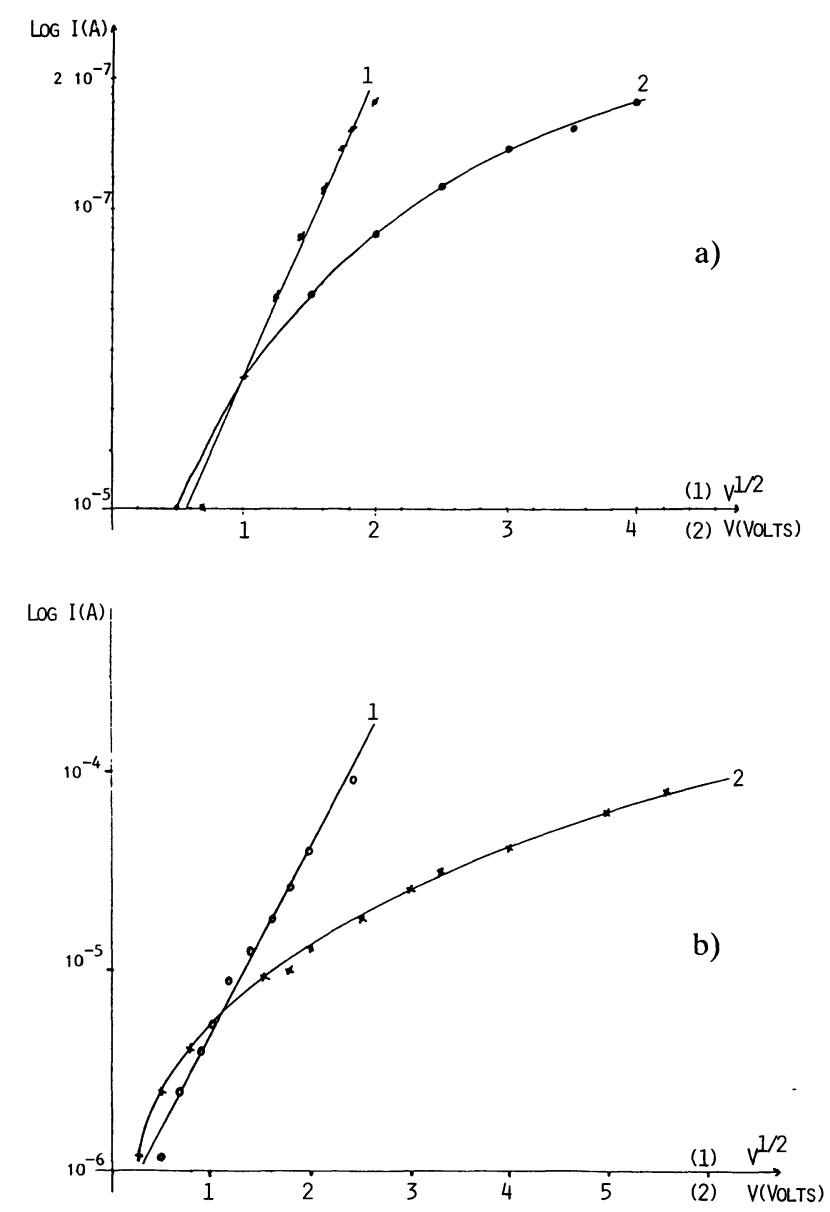

Fig. 7. $-\log I$ versus $V^{12}$ and $V(\mathrm{Au} / \mathrm{ZnPc} / \mathrm{Au}$ cell) (a) and $\left(\mathrm{Au} / \mathrm{ZnPc}\right.$, DIPS $\left.\left.\phi_{4} / \mathrm{Au}\right)(\mathrm{b}) ; 1\right) \log I$ versus $V^{1 / 2}$; 2) Log $I$ versus $V$.

2.5 AC MEASUREMENTS. - Electrical AC measurements of TCNQ and DIPS $\phi_{4}$ doped samples and $\mathrm{AC}$ measurements of $\mathrm{PcZn}$ undoped samples with a low applied voltage (amplitude $0.1 \mathrm{~V}$ ) were made in a large frequency and temperature ranges [19], (Figs. 8-10).

In the limit of ohmicity a correspondence is found between capacity measurements and total depolarization charge [11].

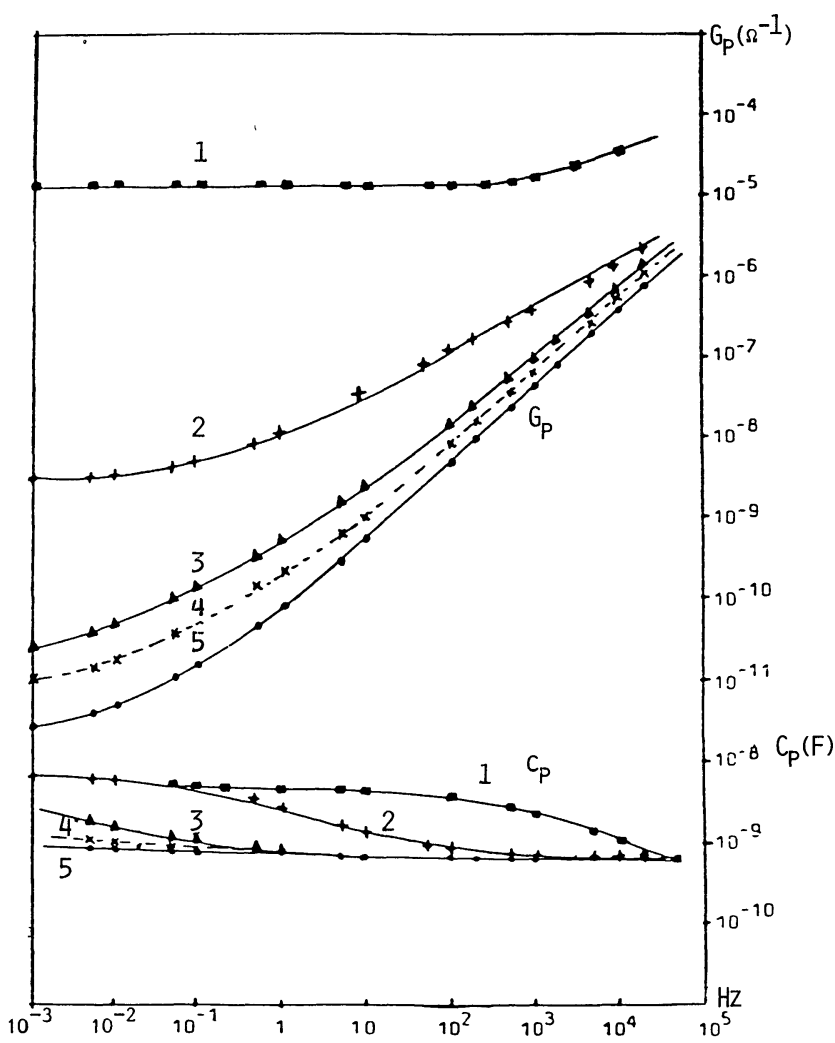

Fig. 8. - Dielectric spectrum of Au/ZnPc, DIPS $\phi_{4} / \mathrm{Au}$ cell for various temperatures ; 1) $295 \mathrm{~K}$; 2) $178 \mathrm{~K}$; 3) $123 \mathrm{~K}$; 4) $109 \mathrm{~K}$; 5) $88 \mathrm{~K}$.

\section{Interpretation of the TSC results.}

3.1 EXPRESSION OF THERMOSTIMULATED CURRENTS. - In the following, some symbols are used (for a $n$ doping).

$N_{\mathrm{t}}$ : density of traps, $E_{\mathrm{t}}$ energy

$\beta \quad$ : heating rate (degrees/second)

$n_{\text {to }}:$ initial density of filled traps

$n_{\mathrm{t}} \quad:$ density of filled traps at $T$

$n_{\mathrm{c}}:$ density of free charges

$v_{\text {th }}:$ thermal velocity

$\nu$ : attempt of escape frequency of trapped charges : $\nu=N_{\mathrm{t}} S_{\mathrm{t}} v_{\mathrm{th}^{\prime}}$

$S_{\mathrm{t}} \quad$ : capture cross section

$\tau$ : recombination time

$d$ : sample thickness

$F \quad$ : applied field.

A single set of electron traps is assumed with doped samples, their energy level $E_{\mathrm{t}}$ is characteristic of the dopant. The thermally stimulated current density $J(T)$ is given by the following system : 


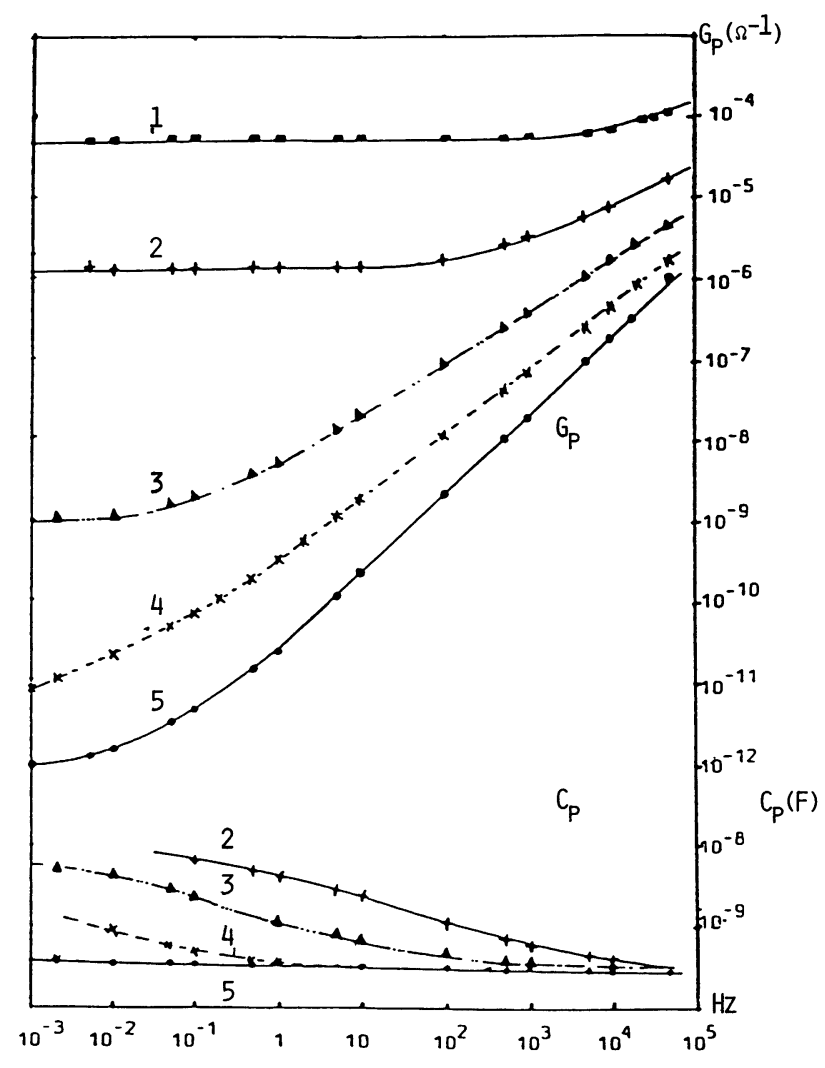

Fig. 9. - Dielectric spectrum of $\mathrm{Au} / \mathrm{ZnPc}, \mathrm{TCNQ} / \mathrm{Au}$ cell for various temperatures ; 1) $295 \mathrm{~K}$; 2) $245 \mathrm{~K}$; 3) $183 \mathrm{~K}$; 4) $141 \mathrm{~K}$; 5) $91 \mathrm{~K}$.

$J(T)=n_{\mathrm{c}} e m F$ ( $m:$ mobility $; e:$ electronic charge)

$$
T=T_{0}+\beta t
$$

( $T_{0}$ being the lowest temperature before the temperature rise)

$$
\begin{aligned}
\mathrm{d} n_{\mathrm{c}} / \mathrm{d} t=-\mathrm{d} n_{\mathrm{t}} / n_{\mathrm{c}} / \tau \\
\mathrm{d} n_{\mathrm{t}} / \mathrm{d} t=-n_{\mathrm{t}} \nu \exp -E_{\mathrm{t}} / k T+ \\
+n_{\mathrm{c}}\left(N_{\mathrm{t}}-n_{\mathrm{t}}\right) S_{\mathrm{t}} v_{\mathrm{th}} .
\end{aligned}
$$

The integration of these equations (2-5) is analytically available only in three cases $[3,12]$.

1) Quick carrier retrapping $\left(N_{\mathrm{t}}-n_{\mathrm{t}}\right) S_{\mathrm{t}} \boldsymbol{v}_{\mathrm{th}} \gg 1 / \tau$.

2) Slow retrapping $\left(N_{\mathrm{t}}-n_{\mathrm{t}}\right) S_{\mathrm{t}} v_{\text {th }} \ll 1 / \tau$.

3) No retrapping, the charges being swept out by the electric field.

The TSC are independent on the applied voltage : the detrapped carrier are swept out into the electrode without retrapping or recombination and so the third hypothesis seems likely with $V>0.5 \mathrm{~V}$.

The current density is then given by [3] :

$$
\begin{aligned}
J(T)=\frac{e d n_{\mathrm{t} 0}}{2} \nu_{\exp } \mid-\frac{E_{\mathrm{t}}}{k T}-\frac{\nu}{\beta} \times & \\
& \times \int_{T_{0}}^{T} \exp \left(-\frac{E_{\mathrm{t}}}{k T^{\prime}}\right) \mathrm{d} T^{\prime} \mid .
\end{aligned}
$$

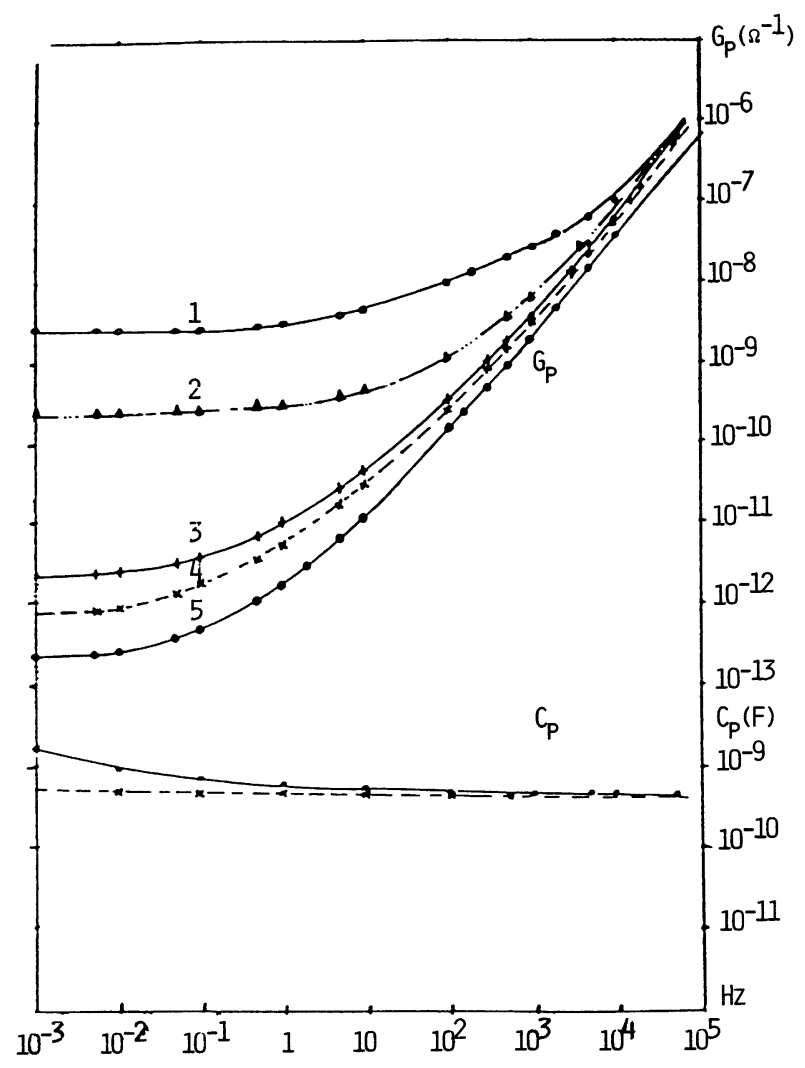

Fig. 10. - Dielectric spectrum of $\mathrm{Au} / \mathrm{ZnPc} / \mathrm{Au}$ cell for various temperatures ; 1) $295 \mathrm{~K}$; 2) $273 \mathrm{~K}$; 3) $215 \mathrm{~K}$; 4) $201 \mathrm{~K}$; 5) $120 \mathrm{~K}$.

By integration of (6) we get the total charge :

$$
\mathrm{Q}=\int_{0}^{\infty} J(T) \mathrm{d} T=\frac{e d}{2} n_{\mathrm{t} 0}
$$

In the case of high fields and no retrapping Mizutami et al. [3] give the values of $A, B$ and A/B

$$
A=\frac{e d n_{\mathrm{t} 0} \nu}{2}, \quad B=\nu, \quad \frac{A}{B}=\frac{e d n_{\mathrm{t} 0}}{2}=Q
$$

we have :

$J(T)=A \exp \left|-\frac{E_{\mathrm{t}}}{k T}-\frac{B}{\beta} \int_{T_{0}}^{T} \exp \left(-\frac{E_{\mathrm{t}}}{k T^{\prime}}\right) \mathrm{d} T^{\prime}\right|$.

The thermocurrent maximum is given by :

$$
J_{\mathrm{m}}=\frac{A}{2.7} \frac{\beta}{B} \frac{E_{\mathrm{t}}}{k T_{\mathrm{m}}} \quad \text { with } \quad \frac{\beta}{B} \sim \frac{k T_{\mathrm{m}}^{2}}{E_{\mathrm{t}} \exp \frac{E_{\mathrm{t}}}{k T_{\mathrm{m}}}} .
$$

On the whole the procedure for determining trapping parameters is the same as used by Mizutami et al. [3] ; from the initial rise, $A$ and $E_{\mathrm{t}}$ can be evaluated, the TSC peak gives $J_{\mathrm{m}}$ and $T_{\mathrm{m}}$ and consequently $A / B$ and $B$. From $Q$ (aera of thermocurrent peak) the initial density of trapped car- 
riers can be evaluated because the retrapping is negligible ; and then trap parameters $\nu, N_{\mathrm{t}}, S_{\mathrm{t}}$ and $\tau$ can be obtained. With voltages $<0.5 \mathrm{~V}$, the TSC peak is linear with $V$ and the mobility $\mu$ can be evaluated.

\subsection{SATURATION EFFECT (DOPED SAMPLES). -} When $V>0.5 \mathrm{~V}$, a saturation appears with a lowering of the temperature of the TSC peak. Chen [13], Zielinski and Samoc [14], Kulshresta and Saunders [15] pointed out two possibilities : first the mobility of charge carriers can vary with the electric field ; second hypothesis, more likely with phthalocyanines [14] is a Poole Frenkel lowering of the trap depth

$$
E_{\mathrm{t}}=E_{\mathrm{t} 0}-\beta_{\mathrm{PF}} F^{1 / 2}
$$

$E_{\mathrm{t} 0}$ is the trap depth without applied field $\beta_{\mathrm{PF}}$ is the Poole Frenkel coefficient.

It is often difficult to distinguish Poole Frenkel effect (field assisted detrapping in the bulk) from Schottky effect (lowering of the electrode field by an applied voltage). In usual $I(V)$ measurements on numerous dielectric materials, the experimental $\beta_{\mathrm{PF}}$ coefficient is rarely exactly found, but often a weaker value lying between Poole Frenkel and Schottky coefficients $\left(2-4 \times 10^{-5}(\mathrm{Vm})^{1 / 2}\right)$.

The various values of $E_{\mathrm{t}}$ obtained by using different methods (initial slope, activation energy of $\tau_{1}(T)=P(T) / J(T)$, where $P(T)$ is the polarisation, Grossweiner method [16]) lead to a rather satisfactory agreement. Equation (9) affords the variation of $E_{\mathrm{t}}$ with $F$ and from (9) we get $\beta_{\mathrm{PF}}=2 \times 10^{-5}(\mathrm{Vm})^{1 / 2}$.
Moreover

$$
T_{\mathrm{m}}=\frac{E_{\mathrm{t}}}{k \operatorname{Ln} B \frac{k T_{\mathrm{m}}^{2}}{\beta E_{\mathrm{t}}}}=\frac{E_{T_{0}}}{k C}-\frac{\beta_{\mathrm{PF}^{1 / 2}}^{\prime}}{k C}
$$

where

$$
C=\operatorname{Ln} \frac{B k T_{\mathrm{m}}^{2}}{\beta\left(E_{0}-\beta_{\mathrm{PF}} F^{1 / 2}\right)} .
$$

$C$ is almost constant versus $F$, and $T_{\mathrm{m}}$ versus $F$ is given on figure 6 . The extrapolation of $T_{\mathrm{m}}$ to $T_{\mathrm{m}_{0}}$ (corresponding to $F=0$ ) gives $E_{T_{0}} / k C$ and the slope of $T_{\mathrm{m}}=f\left(F^{1 / 2}\right)$ gives $\beta_{\mathrm{PF}} / k C$. So we have a complementary $\beta_{\mathrm{PF}}$ determination. This second method yields a somewhat lower value of $\beta_{\mathrm{PF}}$ $\left(1.4 \times 10^{-5}(\mathrm{Vm})^{1 / 2}\right)$.

On table I some values of $T_{\max }, T_{1}$ and $T_{1}^{\prime}$ $\left(I_{\mathrm{TSC}}=I_{\max } / 2\right) E_{T}, \sigma_{\mathrm{RT}}$ (room temperature conductivity), $Q$ and $n_{\mathrm{t} 0}$ are given. The mean relaxation time is defined by :

$\tau_{\mathrm{m}}=P\left(T_{\mathrm{m}}\right) / J\left(T_{\mathrm{m}}\right)$. Some other parameters are also given : first the mobility $\mu$ from the hypothesis that carrier detrapping is the only carrier source. In table I, $n_{\mathrm{t} 0}$ has been evaluated from TSC curves and the conductivity at every temperature is given by $\sigma=n_{\mathrm{t} 0} \mu e$.

The capture cross sections are weak $\left(10^{-22} \mathrm{~cm}^{2}\right.$ to $10^{-24} \mathrm{~cm}^{2}$ with the sample doped with DIPS $\phi_{4}$ ). This very low value is in a good agreement with the third hypothesis of paragraph 3.1 : very weak or no retrapping.

As previously pointed out, DC curves also agree

\begin{tabular}{|c|c|c|c|c|c|c|c|c|c|c|}
\hline & $\begin{array}{ll}S & \beta(S)\end{array}$ & $V_{\mathrm{p}}(\mathrm{V})$ & $T_{\mathrm{m}}(\mathrm{K})$ & $T_{1}(\mathrm{~K})$ & $\left|T_{1}^{\prime}(\mathrm{K})\right|$ & $E_{\mathrm{t}}$ & $Q_{\mathrm{T}}(\mathrm{nc})$ & $\begin{array}{c}\sigma_{\mathrm{RI} I}(\Omega \mathrm{cm})^{-} \\
\mathrm{DC}\end{array}$ & $n n_{10}\left(\mathrm{~cm}^{-3}\right)$ & $\mu\left(\mathrm{cm}^{2} / \mathrm{Vs}\right)$ \\
\hline PcZn & $2 \mu 18 \mathrm{~mm}^{2} 0.066$ & $\begin{array}{c}5 \\
510 \\
20\end{array}$ & $\begin{array}{l}238 \\
237 \\
238\end{array}$ & \begin{tabular}{|l|}
214 \\
210 \\
219
\end{tabular} & \begin{tabular}{|l|}
231 \\
219 \\
237
\end{tabular} & $\begin{array}{l}0.276 \\
0.239 \\
0.35\end{array}$ & $\begin{array}{l}13 \\
16 \\
18\end{array}$ & $1.4 \times 10^{-10}$ & $3 \times 10^{15}$ & $2 \times 10^{-7}(273 \mathrm{~K})$ \\
\hline PcZn TCNQ $20 \%$ & $1.2 \mu 10 \mathrm{~mm}^{2} 0.066$ & $\begin{array}{l}0.5 \\
1 \\
2\end{array}$ & $\begin{array}{l}161.5 \\
159 \\
158\end{array}$ & \begin{tabular}{|l}
140.5 \\
136 \\
133
\end{tabular} & \begin{tabular}{|l|}
155.5 \\
153 \\
153
\end{tabular} & $\begin{array}{l}0.14 \\
0.122 \\
0.11\end{array}$ & $\begin{array}{l}3.7 \\
4.3 \\
4.5\end{array}$ & $6 \times 10^{-6}$ & $5 \times 10^{14}$ & $1 \times 10^{-3}(223 \mathrm{~K})$ \\
\hline PcZn TCNQ & $1.2 \mu 10 \mathrm{~mm}^{2} 0.066$ & $\begin{array}{l}0.5 \\
1\end{array}$ & $\begin{array}{l}176 \\
172\end{array}$ & \begin{tabular}{|l}
154 \\
148
\end{tabular} & $\begin{array}{l}172.5 \\
165\end{array}$ & $\mid \begin{array}{l}0.16 \\
0.138\end{array}$ & $\begin{array}{l}2.15 \\
2.4\end{array}$ & $1.5 \times 10^{-6}$ & & \\
\hline PcZn DIPS 10\% & $1.2 \mu 15 \mathrm{~mm}^{2} 0.066$ & $\begin{array}{l}0.25 \\
0.5 \\
1 \\
2\end{array}$ & $\begin{array}{l}145.5 \\
136 \\
133 \\
130\end{array}$ & \begin{tabular}{|l|}
123 \\
119 \\
114 \\
109
\end{tabular} & $\begin{array}{l}141 \\
128 \\
123 \\
121\end{array}$ & $\mid \begin{array}{l}0.133 \\
0.128 \\
0.11 \\
0.087\end{array}$ & $\begin{array}{l}3.1 \\
4.3 \\
4.5 \\
5\end{array}$ & $3 \times 10^{-7}$ & $6 \times 10^{14}$ & $2 \times 10^{-4}(180 \mathrm{~K})$ \\
\hline PcZn DIPS $\sim 10 \%$ & $1.2 \mu 15 \mathrm{~mm}^{2} 0.066$ & $\begin{array}{l}1 \\
2 \\
4 \\
6\end{array}$ & $\begin{array}{l}128 \\
126 \\
122.5\end{array}$ & \begin{tabular}{|l|}
110 \\
108 \\
100
\end{tabular} & \begin{tabular}{|l|}
121 \\
116 \\
112.5
\end{tabular} & \begin{tabular}{|l}
0.11 \\
0.098 \\
0.070
\end{tabular} & $\begin{array}{l}4.6 \\
5.5 \\
6\end{array}$ & $3 \times 10^{-7}$ & & \\
\hline
\end{tabular}
with a Poole Frenkel mechanism in a relatively short

Table I. - Most important results from the TSC and AC measurements. 
voltage range $(0.5-2 \mathrm{~V})$ with undoped and doped samples, in the whole studied temperature range.

\section{Discussion.}

4.1 UNDOPED SAMPLES. - The electrical properties of phthalocyanines have been thoroughly studied, especially $\mathrm{H}_{2} \mathrm{Pc}$. In undoped samples the electron trap depth $0.37 \mathrm{eV}$ was found by many authors. Devaux and Mas [17] studied $\mathrm{H}_{2} \mathrm{Pc}, \mathrm{NiPc}, \mathrm{CuPc}$ and found a depth near $0.37 \mathrm{eV}$, a shallower trap being found in $\mathrm{ZnPc}(0.3 \mathrm{eV})$. With $\beta \mathrm{ZnPC}$, Abdel Malik et al. [18] have also found a trap depth of $0.37 \mathrm{eV}$ with a very high trap density. Yoshino et al. [5] with TSC method observed traps in $\mathrm{ZnPc}$ located at $0.37+0.03 \mathrm{eV}$.

All these experiments were carried out in vacuum and this is important because Oxygen introduces states in the gap of phthalocyanines [19]. A very small pressure of Oxygen is enough to dope the $\mathrm{ZnPc}$ samples. All the samples are prepared by sublimation exept the monocrystals in wich the same activation energy of conductivity was found, but sublimation was also used in this case before the crystal elaboration, for the material purification. And so a weak decomposition of $\mathrm{ZnPc}$ during the sublimation process may be possible : however when the samples remain a long time in a good vacuum $\left(10^{-7}\right.$ Torr) their conductivity decreases, while the activation energy remains quite constant, so that the Oxygen origin of $0.37 \mathrm{eV}$ traps in $\mathrm{ZnPc}$ is quite likely.

Three voltage ranges are pointed out : low voltage range $(V<0.5 \mathrm{~V})$ with an ohmic conductivity, $0.5 \mathrm{~V}<V<2.5 \mathrm{~V}$ where a Poole Frenkel effect is seen and $V>2.5 \mathrm{~V}$ where injection from electrodes is the chief phenomenon. The reason of linearity of the thermocurrent peak versus $V$ in this third range is the following: when $I_{\mathrm{DC}}$ varies as $V^{2}$, a great deal of traps are filled and the trapped charge density is about constant through the sample. For each depth value the electric field is in direct ratio with $n_{\mathrm{t}}$ and so the applied potential is also proportional to. $n_{\mathrm{t}}$

4.2 DOPED SAMPLES. - As far as we know, deliberately doped samples were scarcely studied in literature. Y. Hoshino [6] found well defined trap levels when $\mathrm{CuPc}$ is dispersed in an insulating resin, and more recently [12] Y. I. Takada and coworkers found in $\mathrm{Al} / \mathrm{AlClPc} / \mathrm{Al}$ cells shallow traps using the TSC method. In these cells, Chlorine is introduced and likely acts as a doping agent, though chemically linked to AlPc.

In all the cases, even when two molecular materials are coevaporated it can be anticipated from the Lyons model that $n$ or $p$ doping is thoroughly equivalent to the reduction or oxydization of the host molecules and a chemical bond between dopant and doped molecules is created. On the other hand, the doping efficiency is linked to the mass action law : we have (for $p$ doping)

$$
\begin{gathered}
K=\left(\mathrm{PcZn}^{+}\right)\left(\text {dopant }^{-}\right) /(\mathrm{PcZn})(\text { dopant }) \\
\text { with } \operatorname{Ln} K=\left(E^{\mathrm{red}}-E^{\mathrm{ox}}\right) / 0.059
\end{gathered}
$$

Consequently the efficiency of doping is generally low. The intrinsic density of charge carriers is very low in MPc $\left(10^{14} / \mathrm{m}^{3}\right)$ [20] and so, even weak acceptor or donor molecules can give high conduction increases.

The charge released in TSC and the capacity measured in the low or very low frequency range are tightly linked a low voltages $<0.5 \mathrm{~V}$. Gibbs and Long [21] pointed out that in disordered materials with ohmic electrodes the capacity at a low frequency gives the Debye length $L_{\mathrm{D}}: C=\varepsilon / L_{\mathrm{D}}$, where $\varepsilon$ is the permittivity of the sample and $L_{\mathrm{D}}=$ $\left(\varepsilon k T / N e^{2}\right)^{1 / 2}, N$ being the carrier density (density of carriers hopping between traps).

A first evaluation of $N$ (and $N e$ ) is then compared with the total aera of the TSC curve. The two evaluations are in a rather good agreement : with DIPS $\phi_{4}$ we have from TSC, $N=5 \times 10^{20} / \mathrm{m}^{3}$ and from $L_{\mathrm{D}}, N=10^{21} / \mathrm{m}^{3}$. However the $\mathrm{ZnPc}$ density is near $3 \times 10^{27}$ molecules $/ \mathrm{m}^{3}$. A doping ratio of $10 \%$ in moles (DIPS $\phi_{4}$ ) gives $3 \times 10^{26} / \mathrm{m}^{3}$ molecules of dopant and an efficiency of $10^{-5}$. The efficiency of TCNQ doping is somewhat higher.

From [13], a weaker efficiency is obtained likely because $E^{\text {red }}$ and $E^{\text {ox }}$ are somewhat different in solid state and in solution.

On the whole, the doping of molecular materials appears as a thoroughly different process on regard to covalent mineral semiconductors doping. Much higher dopant ratios are necessary in molecular semiconductors to get good conductivities.

At last the carrier density seems independent on temperature: only the mobility is activated. We have in table I some mobility values (calculated with the hypothesis of no injection by the contacts). Because the mobility is directly linked to detrapping, and the trap depth is a function of the electric field (Poole Frenkel effect), the mobility appears as field dependent, and increases with electric field. The two proposed models [13-15], Poole Frenkel effect and mobility varying with voltage are in fact two aspects of the same phenomenon: in many disordered molecular solids, this conclusion is very likely.

4.3 DC AND AC RESUlTs. - The curves Log $I$ versus $V$ and versus $V^{1 / 2}$ are given figure 7 for two doped samples. In the range 0.5 to $1.5 \mathrm{~V}$, the Poole Frenkel mechanism is in a fairly good acquaintance to the data.

On the other hand, the AC conductance $\left(G_{\mathrm{p}}=1 / R_{\mathrm{p}}\right)$ and capacity $C_{\mathrm{p}}$, equivalent to the 
sample in the parallel representation are given on figures 8, 9, 10 (DIPS, TCNQ doped and undoped samples), versus frequency. Two parts are seen in the $G_{\mathrm{p}}$ curves : in the low temperature and high frequency range, a hopping conductivity with a slope of $\log G_{\mathrm{p}}$ versus $f=-1$ is seen and with a low activation energy. In the low frequency range, $G_{\mathrm{p}}$ turns into the DC conductance value with an activation energy very near the value computed from the TCD curves.

It would be inferred from these data that the DC conductivity is a percolation phenomenon, the traps due to the chemical impurity being characteristic of the dopant. These trapping states are the limiting factor of the conductivity, and correspond to the most difficult carrier hops to get a long range conductivity.

The hopping probability, and so the mobility are dependent on the energy level of the traps and so the mobility and not only the carrier density can be improved by doping.

\section{Conclusion.}

The doping of ZnPc by $p$ or $n$ molecular materials can be profitably studied by the TSC and AC methods. However a great deal of work must yet be done : the variation of mobility (at weak electric fields) with doping ratio, dopant and host nature will be the subject of further work. However the ability of doping $\mathrm{ZnPc}$ by TCNQ and DIPS $\phi_{4}$ theoretically predicted was experimentally accomplished.

\section{Acknowledgments.}

We are very endebted to J. J. André for $\mathrm{ZnPc}$ purifications and to H. Strezlecka for DIPS $\phi_{4}$ synthetization. This work was made within the GRIMM (Groupement de Recherches Interdisciplinaires sur les Matériaux Moléculaires).

\section{References}

[1] VAN TURNHOUT, J., Thermally stimulated discharge of polymer electrets, Elsevier (1975).

[2] CHEN, R. and KIRSH, Y., Analysis of Thermally stimulated process, Pergamon Press (1981).

[3] Mizutami, T., Suzuoki, Y., Hanai, M. and Ieda, M., Jpn. J. Appl. Phys. 21 (1982) 1639.

[4] Westgate, C. R. and Warfield, G., J. Chem. Phys. 46 (1967) 537.

[5] Yoshino, K., Kaneto, K., TAtsuno, K. and INUISHI, Y., J. Phys. Soc. Jpn. 35 (1973) 120.

[6] Hoshino, Y., J. Appl. Phys. 52 (1981) 5655.

[7] Lyons, L. E. Aust. J. Chem. 33 (1980) 1717.

[8] Simon, J. and ANDre, J. J. Molecular Semiconductors, Springer Verlag (1985).

Boudjema, B., Thèse de Doctorat d'Etat, Lyon (1987).

[9] El-KhatiB, N., Thèse de Doctorat, Lyon (1986).

[10] El-Khatib, N., Maitrot, M., Chermette, H., Porte, L. and Strezlecka, H., to be published ;

El-Khatib, N., Chermette, H., Boudjema, B., MAITROT, M. and PORTE, L., submitted to publication.
[11] Gamoudi, M., Thèse de Doctorat d'Etat, Lyon (1986).

[12] Tageda, Y. I., Kinjo, N., Narahara, T., J. Mater. Sci. Lett. 4 (1985) 80.

[13] Chen, I., J. Appl. Phys. 47 (1976) pp. 2988-2994.

Chen, I. and SLowiK, J. N., Solid State Comm. 17 (1975) 783.

[14] Zielinski M. and Zamoc, M., J. Phys. D (Appl. Phys.) 10 (1978) L105.

[15] Kulshrest, A. P., and Saunders, J. L., J. Phys. D (Appl. Phys.) 8 (1975) 1787.

[16] Grossweiner, J., J. Appl. Phys. 24 (1953) 1306.

[17] Devaux, P. and Mas, J. Solid State Comm. 7 (1976) 1095.

[18] Abdel Malik, T. G., Aedeen, A. M. and El Labany, H. M., Phys. Status Solidi 72 (1982) 99.

[19] Guillaud, G., Thèse de Doctorat d'Etat, Lyon (1984).

[20] Simon, J., Andre, J. J. and MAitrot, M., Molecules in Physics, Chemistry and Biology Reidel pub. (to be published 1987).

[21] Gibis, I. G. and Long, A. R., Philos. Mag. B 49 (1984) 565. 